\title{
COVID-19's Negative Impacts on Clinical Learning and Proposed Compensation Mechanisms Among Undergraduate Midwifery and Nursing Students of Jimma University
}

\author{
Kebenesa Angasu (iD) \\ Tariku Bekela (D) \\ Melkamu Gelan' \\ Diriba Wakjira' \\ Eneyew Melkamu' \\ Berhanu Belachew' \\ Tujuba Diribsa ${ }^{1,2}$ \\ Abdulwahid Awol Ahmed (ID) \\ Abdisa Eba ${ }^{1-3}$ \\ Kenenisa Tadesse ${ }^{1-4}$ \\ Bekele Boche ${ }^{1-5}$ \\ 'Department of Midwifery, Jimma \\ University, Jimma, Ethiopia; ${ }^{2}$ Department \\ of Reproductive Health, Jimma University, \\ Jimma, Ethiopia; ${ }^{3}$ Department of Nursing, \\ Jimma University, Jimma, Ethiopia; \\ ${ }^{4}$ Department of Statistics, Jimma \\ University, Jimma, Ethiopia; ${ }^{5}$ Department \\ of Pharmacy, Jimma University, Jimma, \\ Ethiopia
}

\begin{abstract}
Background: Even though lockdown measures contributed to reducing the rate of COVID-19 transmission, it resulted in great distraction in clinical learning. Thus, the aim of this study was to assess COVID-19's negative impacts on clinical learning, and proposed compensation mechanisms among midwifery and nursing undergraduate students of Jimma University, southwest Ethiopia.
\end{abstract}

Methods: This study was conducted among 147 midwifery and nursing students of Jimma University in March 2021 using cross-sectional study design. The respondents were selected by simple random sampling method. Data were collected by using a self-administered questionnaire and analyzed descriptively by SPSS v.23. The results were presented in tables, and narrated.

Results: Three fifths (88 (59.9\%)) of the study participants perceived high negative impacts of COVID-19 on their recent clinical learning. The proposed compensation mechanisms to be implemented before and during the next clinical practice include: using teacher-facilitated skill demonstration laboratory, case scenarios, clinical teaching videos, and clinical conferences. Students' effort to understand the objectives of their clinical learning and using multimedia to achieve it was another proposed compensation mechanism. Also, providing preplacement training and in-service training with priority for students graduating during COVID-19 pandemic were proposed compensation mechanisms.

Conclusion: COVID-19's negative impacts on clinical learning were great among the participants of this study. The proposed compensation mechanisms should be applied by all concerned bodies with great emphasis to end the long-term negative impact of the pandemic, thereby ensuring the production of competent midwives and nurses.

Keywords: Covid-19's negative impacts, compensation mechanisms, clinical learning, Jimma University

\section{Introduction}

Globally, Coronavirus disease 2019 (COVID-19) has had great negative consequences for higher education such as universities closing in response to lockdown measures. ${ }^{1-3}$ In Ethiopia, the first COVID-19 case was confirmed on 13/3/2020. ${ }^{4}$ In response to the steady spread of the disease in the country, the Ethiopian national government declared a state of emergency during which educational institutions closed and stopped their usual teaching and learning processes for eight months from March to November $2020 .^{5}$
Correspondence: Kebenesa Angasu Tel +251919841766

Email kebenesa2019@gmail.com 
To compensate for the educational period which passed during the state of emergency, undergraduate health science students of Jimma University (JU) including nursing and midwifery students had to learn clinical courses in a short period of time for the purpose of regaining their usual academic calendar and graduating in time. Thus, it was almost impossible for them to achieve their accreditation standards for graduation in terms of clinical practice. So they are prone to having deficit clinical competencies amplifying the provision of ineffective care with serious harmful consequences on their patients and clients in their future professional life. ${ }^{6-8}$

This implies that certain compensation mechanisms should be in place to build up and strengthen clinical skills of the current midwifery and nursing students of JU. As a result, it is better for students who graduated during the pandemic to work in health care facilities as interns for a certain period of time until they become clinically competent. ${ }^{3}$ To better facilitate clinical learning of midwifery and nursing students, clinical educators' optimal guidance, motivation, and emotional support are compulsory. ${ }^{9}$ Yet the clinical teachers' commitment and motivation toward clinical teaching can also be in question as a result of COVID-19.

Even if the degree of their involvement differs, both midwives and nurses have great responsibility in reducing maternal and neonatal deaths which are major indicators of a country's development. ${ }^{10}$ It implies the quality of both midwifery and nursing clinical learning, that enables them to be effective midwives and nurses, which is essential. ${ }^{8,11,12}$ In line with this, Ethiopia has urgent need for competent midwifery and nursing professionals. ${ }^{13}$

In addition to shortened clinical learning time during the current COVID-19 era, students are also at risk of being infected and carrying infection among clients and patients in the clinical area. ${ }^{3}$ Also, living in the pandemic era can negatively affect learners' determination and commitment to their clinical training and emotional interaction with their clients/patients which can also affect effectiveness of their clinical learning. ${ }^{9}$

Even though previous studies identified some impacts of COVID-19 on clinical education and suggested ways to support students' clinical learning, ${ }^{3,9}$ they were limited in solving the challenging situation specific to them. Studies done on impact of the pandemic on clinical learning and compensation mechanisms for ending its longterm effect are important for the future. Thus, the aim of this study was to assess COVID-19's negative impacts on clinical learning and proposed compensation mechanisms among midwifery and nursing undergraduate students of Jimma University. Its findings contribute new insight on the issue. The proposed compensation mechanisms for enhancing students' clinical competence play a very significant role to end the long-term impact of COVID-19. Thus, this study has great importance and is urgent to direct the way forward.

\section{Methods}

\section{Study Area, Design, and Period}

This study was conducted in two schools (school of midwifery and a school of nursing) of JU which is among the leading universities in Ethiopia. JU currently teaches more than 46,000 students. During this study period, there were ninety-three, and one hundred and forty-three regular undergraduate third and fourth year students in school of midwifery and school of nursing of JU respectively. As part of all students' curriculum under faculty of health and medical sciences, students of both school of midwifery and nursing recently had their clinical practicum in Jimma University Medical Center, which is a very overcrowded hospital. The fourth year students of both school of midwifery and nursing had their first internship clinical practicum which lasted only 17 days, but was supposed to last over 56 days of their curriculum. Also, the third year students of both schools had their clinical course practicum days reduced by half compared to duration scheduled on their curriculum. This study was undertaken from March 25 to 30/2021 by using institution-based quantitative cross-sectional study design.

\section{Source Population}

The source population of this study was all regular undergraduate third and fourth-year midwifery and nursing students of JU.

\section{Study Population}

The study population was all sampled regular undergraduate third and fourth-year midwifery and nursing students of JU.

\section{Inclusion and Exclusion Criteria}

The inclusion criteria were: being the study population of this study and being available in the campus during the data collection period. The exclusion criteria were: having 
re-exam and severe illness during the data collection period of this study.

\section{Sample Size Determination and Sampling Method}

To determine the sample size, we used single population proportion formula $\left(n=\left(z^{2} p(1-p) / E^{2}\right)\right)$. Where: $n-$ is required sample size; $z$ - is the critical value at $95 \%$ confidence level thus 1.96; p-proportion of midwifery and nursing students who perceived high negative COVID-19 impacts on clinical learning was taken as $50 \%$ due to lack of relevant previous study and for gaining relatively larger sample size; E- sampling error taken as 5\%. Thus, $\mathrm{n}=$ $1.96^{2} * 0.5 * 0.5 / 0.05^{2} ; \mathrm{n}=384.16$. Since our total population was less than 10,000 , we used correction formula $(\mathrm{nf}=\mathrm{n} * \mathrm{~N} / \mathrm{n}+\mathrm{N})$ to further reduce the sample size. Where: nf- sample size, $\mathrm{n}$ - is the initial sample size thus 384.16 ; $\mathrm{N}$ - is the population size thus 236 . Thus, $\mathrm{nf}=384.16 * 236$ / $384.16+236$. Finally resulting in $n f=146.2 \approx 147$. Then the sample size was proportionally allocated for third and fourth-year students of both schools. After all, to randomly select the specific participants, simple random sampling method was used. Sampling frame was the students' list taken from their registrar.

\section{Data Collection Instrument and Pre-Test}

Our data collection instrument was a self-administered semi-structured questionnaire established after reviewing relevant literature. ${ }^{6,12,14-17}$ It involved three sections: socio-demographic characteristics (nine questions), COVID-19's negative impacts on clinical learning (twelve questions), and proposed compensation mechanisms for ending long-term COVID-19 negative impacts on clinical learning (four questions). English version questionnaire was used to collect data. This was because the study participants were university students and they have been learning English starting from grade one to $1^{\text {st }}$ year of their University courses and they were believed to understand English well. The questionnaire was pre-tested among fifteen nursing students of Rift valley University Jimma campus so as to amend its syntax.

\section{Operational Definitions}

COVID-19's negative impacts on clinical learning: the negative consequence of disturbed situations due to COVID-19 and its management on effectiveness of clinical learning.
COVID-19's negative impacts on clinical learning measurement scale: it was measured by students' perception of COVID-19's negative impacts on their clinical learning using twelve items responded to as "yes" or "no" while correct answer was coded ' 1 ' and incorrect coded ' 0 '. The total score summed up making maximum ' 12 ' and minimum ' 0 '. As a result, respondents who scored mean or above $\geq 6$ were considered as "suffered high COVID-19 negative impacts on their clinical learning" and the rest were considered as "suffered low COVID-19 negative impacts on their clinical learning".

\section{Data Collection Method}

The study participants themselves completed the questionnaire by reading it while they were in their usual classroom. Four data collectors (BSc. nurses) and two supervisors (MSc. nurses) facilitated the data collection process after they were trained on data collection tools and methods for a day. Procedurally, data collectors informed all about the study and how the questionnaire should be responded to and they obtained informed written consent. Participants were encouraged to ask any questions they had throughout and a description was provided by the data collectors. The schedule of data collection was arranged by the supervisors.

\section{Data Quality Control}

To ensure data quality, we used pre-tested questionnaire for data collection; we provided 1 day training for data collectors and supervisors; completeness of filled questionnaire was checked throughout by the supervisors; and also we used Epi-data software for entering the data to minimize error.

\section{Data Analysis and Presentation}

Statistical package for Social Sciences (SPSS) version 23 software was used for data analysis. Descriptive analysis was done and the results were presented by tables, and narrated.

\section{Ethical Consideration}

This study was conducted in accordance with the declaration of Helsinki. Ethical approval was obtained from the Institutional Review Board of Jimma University Institute of Health with reference number: IHRPGn/475/. Written informed consent was obtained before commencing data collection. The study participants' anonymity and confidentiality of their information were maintained throughout. 


\section{Results}

\section{Socio-Demographic Characteristics of}

\section{Respondents}

Overall, 147 undergraduate midwifery and nursing students participated with $100 \%$ response rate. Just more than one forth $(66(44.9 \%))$ of respondents were male. Two fifths (58 (39.5\%)) of the study participants were midwifery students while around half $(70(47.6 \%))$ of participants were third year students. Just more than two thirds (107 (72.8\%)) of the study participants stayed with their parents during the lockdown measures for COVID-19 while $21(14.2 \%)$, and $19(13 \%)$ stayed with friends and alone respectively (Table 1$)$.

\section{COVID-19's Impacts on Clinical Learning}

Overall, three fifths $(88(59.9 \%))$ of the study participants perceived high COVID-19 negative impacts on their recent clinical learning. Nearly one tenth $(16(10.9 \%))$ of the study participants reported testing positive for COVID19. Among those $6(4.1 \%), 7(4.8 \%)$, and $3(2 \%)$ tested positive before, during, and after their recent clinical practicum respectively. Nearly one fourth (38 (25.9\%)), and one eighth (19 $(12.9 \%))$ of respondents had family members, loved ones, or close relatives who tested positive for COVID-19 and lost them to death due to COVID-19 respectively. Seven tenths $(103(70.1 \%))$ of respondents had fear of being infected by COVID-19 during their recent clinical practicum from the clinical practice area. More importantly, two thirds (98 $(66.7 \%)$ ) of respondents perceived that fear of being infected by COVID-19 had impaired their clinical learning. Only close to half (76 $(51.7 \%))$ of respondents perceived that their clinical teachers were motivated to teach them during their recent clinical practicum. Just more than half $(82(55.8 \%))$ of respondents perceived that COVID-19 had an influence on reducing their grade during their recent clinical practice (Table 2).

\section{Proposed Compensation Mechanisms to End Long-Term Impacts of COVID-I9 on Clinical Learning}

All 147 (100\%) respondents responded that certain compensation mechanisms should be arranged to cease the long-term negative impacts of COVID-19 on clinical learning. As such, the respondents proposed compensation mechanisms categorized into three as: compensation to be
Table I Socio-Demographic Characteristics of Regular Undergraduate Midwifery and Nursing Students of Jimma Universities, South West Ethiopia, 202I, $(n=147)$

\begin{tabular}{|c|c|c|c|}
\hline Variables & Category & Frequency & Percent (\%) \\
\hline \multirow[t]{2}{*}{ Sex } & Female & 81 & 55.1 \\
\hline & Male & 66 & 44.9 \\
\hline \multirow[t]{2}{*}{ School } & Midwifery & 58 & 39.5 \\
\hline & Nursing & 89 & 60.5 \\
\hline \multirow[t]{2}{*}{ Study year } & Third year & 70 & 47.6 \\
\hline & Fourth year & 77 & 52.4 \\
\hline \multirow[t]{2}{*}{ Residence } & Urban & 93 & 63.3 \\
\hline & Rural & 54 & 36.7 \\
\hline \multirow{3}{*}{$\begin{array}{l}\text { Where they stayed } \\
\text { during lockdown for } \\
\text { COVID-19 }\end{array}$} & $\begin{array}{l}\text { Addis } \\
\text { Ababa }\end{array}$ & 32 & 21.8 \\
\hline & $\begin{array}{l}\text { Other } \\
\text { urban }\end{array}$ & 82 & 55.8 \\
\hline & Rural & 33 & 22.4 \\
\hline \multirow{3}{*}{$\begin{array}{l}\text { With whom the } \\
\text { student was during } \\
\text { the lockdown period }\end{array}$} & $\begin{array}{l}\text { With } \\
\text { parents }\end{array}$ & 107 & 72.8 \\
\hline & $\begin{array}{l}\text { With } \\
\text { friends }\end{array}$ & 21 & 14.2 \\
\hline & Alone & 19 & 13 \\
\hline \multirow[t]{4}{*}{ Religion } & Muslim & 48 & 32.7 \\
\hline & Orthodox & 57 & 38.8 \\
\hline & Protestant & 36 & 24.5 \\
\hline & Others* & 6 & 4 \\
\hline
\end{tabular}

Note: *Indicates religions included under "others" category which are: Wakefata, Adventist, and Apostolic.

Abbreviation: COVID-19, coronavirus disease 2019.

made before and during the next clinical practicum; compensation mechanisms to be taken by the students themselves any time; and compensation mechanisms to be undertaken after their graduation.

Consequently, during their next clinical practicum, greater proportion (116 (78.9\%)) of respondents responded that they should intensively practice the clinical skills in skill demonstration laboratory before they commence their clinical practice in health facilities so as to make their clinical practice effective. Also, greater than half (75 $(54.9 \%))$ of respondents proposed using relevant case scenarios and clinical teaching videos as compensation mechanism for their recent clinical practicum being 
Table 2 Perceived Impacts of COVID-19 on Clinical Learning Among Regular Undergraduate Midwifery and Nursing Students of Jimma University, South West Ethiopia, 2021, $(n=147)$

\begin{tabular}{|c|c|c|c|}
\hline Variables & Categories & Frequency & $\begin{array}{l}\text { Percent } \\
\text { (\%) }\end{array}$ \\
\hline \multirow[t]{2}{*}{ Have you ever tested positive for COVID-19? } & Yes & 16 & 10.9 \\
\hline & No & $13 \mid$ & 89.1 \\
\hline \multirow[t]{2}{*}{ Have you had family members, loved ones, or close relatives who tested positive for COVID-I9? } & Yes & 38 & 25.9 \\
\hline & No & 109 & 74.1 \\
\hline \multirow[t]{2}{*}{ Did you lose family members, loved ones or close relatives due to COVID-19? } & Yes & 19 & 12.9 \\
\hline & No & 128 & 87.1 \\
\hline \multirow[t]{2}{*}{ Do you perceive that duration of your recent clinical practice was not enough due to COVID-I9? } & Yes & 95 & 64.6 \\
\hline & No & 52 & 35.4 \\
\hline \multirow[t]{2}{*}{ Do you perceive that load of student impaired your recent clinical practicum? } & Yes & 112 & 76.2 \\
\hline & No & 35 & 23.8 \\
\hline \multirow[t]{2}{*}{ Have you had fear of being infected by COVID - 19 during your recent clinical practicum? } & Yes & 103 & 70.1 \\
\hline & No & 44 & 29.9 \\
\hline \multirow[t]{2}{*}{ Do you perceive that fear of being infected by COVID-19 has impaired your clinical learning? } & Yes & 98 & 66.7 \\
\hline & No & 49 & 33.3 \\
\hline \multirow[t]{2}{*}{ Do you perceive that your patients had fear of being infected by COVID-19? } & Yes & 106 & 72.1 \\
\hline & No & 41 & 27.9 \\
\hline \multirow{2}{*}{$\begin{array}{l}\text { Do you perceive that you achieved your clinical learning objectives during your recent clinical } \\
\text { practice? }\end{array}$} & Yes & 65 & 44.2 \\
\hline & No & 82 & 55.8 \\
\hline \multirow{2}{*}{$\begin{array}{l}\text { Do you perceive that you were motivated for your clinical learning during your recent clinical } \\
\text { practice? }\end{array}$} & Yes & 69 & 46.9 \\
\hline & No & 78 & 53.1 \\
\hline \multirow{2}{*}{$\begin{array}{l}\text { Do you perceive that your clinical teachers were motivated to teach you during recent clinical } \\
\text { practice? }\end{array}$} & Yes & 76 & 51.7 \\
\hline & No & 71 & 48.3 \\
\hline \multirow{2}{*}{$\begin{array}{l}\text { Do you perceive that COVID- } 19 \text { had an influence on reducing your grade during your recent clinical } \\
\text { practice? }\end{array}$} & Yes & 82 & 55.8 \\
\hline & No & 65 & 44.2 \\
\hline \multirow[t]{2}{*}{ Overall perceived impacts of COVID-I9 on clinical learning } & High & 88 & 59.9 \\
\hline & Low & 59 & 40.1 \\
\hline
\end{tabular}

Abbreviation: COVID-19, coronavirus disease 2019.

negatively affected by COVID-19. In addition, almost half $(72(49 \%))$ of respondents responded that it is better if their clinical teachers arrange pre and post clinical conferences daily to better direct them in their clinical learning and solve any problem timely.

As compensation mechanism to be undertaken by the students themselves, all 147 (100\%) respondents responded that they should understand the objectives of their clinical practicums and should use relevant multi-media to enable them to achieve their clinical learning objectives. Also after their graduation, the majority $(123(83.7 \%))$ of respondents responded that pre-placement training on essential professional clinical skills should be given to them. In addition, nearly half $(80(54.4 \%))$ of participants replied that priority 
in-service training should be arranged for them to compensate for their clinical competence being impaired due to COVID-19.

\section{Discussion}

This study found that a higher proportion (88 (59.9\%)) of study participants perceived that they suffered high COVID-19 negative impacts on their clinical training. In order to cease the progressive COVID-19 negative impacts on their clinical practice, the respondents proposed compensation mechanisms categorized as: compensation to be made before and during their next clinical practicum, compensation to be made by students themselves any time, and compensation to be made after their graduation.

Even if there was no relevant previous study that quantified the level of COVID-19 impact on clinical learning, the result of the current study is consistent with the finding of a study done at Syria Linka where reduction of clinical practice time was believed to reduce both learners' clinical skill and interpersonal communication skill. ${ }^{15}$ High COVID19 negative impact on clinical training is to be expected. ${ }^{7}$ This can be justified by evidence revealed in this study such as, a significantly high proportion of the participants mentioned that their clinical training time was shortened; their own and their teachers' motivation for clinical learning were reduced; and students had fear of getting infected by the pandemic in their clinical practicum area among others. All of this imposed negative impact on their clinical learning.

In this study, compensation mechanisms categorized into three were proposed by the students themselves to end progressive COVID-19 negative impacts on their clinical learning. One of the proposed compensation mechanisms was understanding the objectives of their clinical learning and using multi-media to achieve it. This can have great positive influence on enabling students to improve their clinical competence impaired due to COVID-19 if students committed themselves to undertake it.

The other proposed compensation mechanisms were compensation to be arranged by third parties. Compensation before and during their next clinical practicum include using clinical skill demonstration laboratory before starting clinical practice, pre and post clinical conferences, using relevant case scenarios and clinical teaching videos. The success of all these proposed compensation mechanisms depends on the clinical teachers' preparedness and commitment to facilitate it. ${ }^{16}$ The rest of the proposed compensation mechanisms were gaining pre-placement training, and priority in-service training after their graduation and employment respectively. So, preparing pre-placement training and in-service training need the action of stakeholders committed to end progressive COVID-19 negative impacts among the study participants so as to ensure provision of quality care for communities.

The effectiveness of provision of pre-placement training can be supported by the evidence from other studies where graduates suggested that it was better to work as interns before commencing their clinical care provision as accountable care providers. ${ }^{3}$ In addition, both preplacement and in-service training are believed to have formative influence on clinical competencies of graduates since the graduates train knowing the relevance of the competencies in solving real problems of their society.

\section{Strength and Limitation of This Study}

This study was conducted to identify negative impacts of the current pandemic on clinical learning and also outlined the proposed compensation mechanisms to end long-term negative impacts of COVID-19 on clinical learning. Thus, concerned bodies can gain clear direction to deal with the issue appropriately. Since this study was based on students' perception, it is believed that it also serves as provoking factor to enable the students to see the gap in clinical learning and implement measures to improve their clinical learning. As limitation, since only students were invited to participate in this study, future research should invite clinical educators and other relevant stakeholders to propose compensation mechanisms to alleviate COVID-19's long-term negative impacts on clinical learning.

\section{Conclusion}

As expected, a significantly high proportion of the study participants perceived that they suffered high COVID-19 negative impacts on their clinical training. To end progressive COVID19 negative impacts on their clinical learning, the study participants proposed seven compensation mechanisms. The proposed compensation mechanisms include: intensively using teacher-facilitated skill demonstration laboratory, case scenarios, clinical teaching videos, and using pre and post clinical conferences. Also, students own effort to understand their clinical learning objectives and using multi-media to achieve it whenever they have time was another proposed compensation mechanism. In addition, gaining pre-placement training, and gaining in-service training as primary priority were 
proposed compensation mechanisms to be undertaken after their graduation. Thus, the students themselves, their clinical teachers, and all stakeholders should be committed enough to put each proposed compensation mechanism into practice so as to end progressive COVID-19 negative impacts on clinical learning of the students, thereby contributing to produce a competent health workforce to satisfy the country's demand.

\section{Abbreviations}

CI, confidence interval; COVID-19, corona virus disease2019; JU, Jimma University.

\section{Acknowledgments}

We greatly acknowledge our data collectors and supervisors. Also, we acknowledge our study participants for providing their responses.

\section{Author Contributions}

All authors made a significant contribution to the work reported, whether that is in the conception, study design, execution, acquisition of data, analysis and interpretation, or in all these areas; took part in drafting, revising or critically reviewing the article; gave final approval of the version to be published; have agreed on the journal to which the article has been submitted; and agree to be accountable for all aspects of the work.

\section{Disclosure}

The authors report no conflicts of interest in this work.

\section{References}

1. World health organization. Coronavirus disease 2019 (COVID-19) Situation Report - 94. Available from: www.who.int>docs 20200423sitrep-94-covid-19. Accessed February 27, 2021.

2. Andreas $\mathrm{S}$ The impact of covid-19 on education- Insights from education at a glance 2020. Available from: https $\% 3 \mathrm{~A} \% 2 \mathrm{~F} \% 2 \mathrm{Fwww} .0 e c d$ org\%2Feducation $\% 2$ Fthe-impact-of-covid-19-on-education-insightseducation-at-a-glance-2020.pdf. Accessed February 28, 2021.
3. Akyildiz D. Distance education of midwifery students during the COVID-19 pandemic: challenges and recommendations. Eur J Midwifery. 2021;5:1-2. doi:10.18332/ejm/138594

4. First case of covid-19 confirmed in Ethiopia. WHO Regional Office for Africa. Available from: https://www.afro.who.int/news/first-casecovid-19-confirmed-ethiopia. Accessed February 27, 2021.

5. Elias G University World News Africa edition Ethiopia 22 October, 2020. Classes to resume soon for final-years at state universities. Available from: https://www.universityworldnews.com/post.php? story $=20201021203025367$. Accessed February 27, 2021.

6. Immanuel S, Yaser H, Youssef C, Jubilent A, Nadir H. Understanding the consequence of COVID-19 on undergraduate medical education: medical students' perspective. Ann Med Surg. 2020;58:117-119.

7. Ferrel MN, Ryan JJ. The impact of COVID-19 on medical education. Cureus. 2020;12(3):e7492. doi:10.7759/cureus.7492

8. Kobekyaa FK, Markhosizana BD, Bagrmwin L, et al. Current Issues and challenges of clinical education in nursing and midwifery in Africa: protocol of a scoping review study. Nur Primary Care. 2019;3(2):1-5.

9. Tay YX, Chow HC, Ooi CC. Impact on clinical learning during coronavirus disease 2019 pandemic: from disruption to recovery and the new norms. Korean J Med Educ. 2020;32(4):297-305. doi:10.3946/kjme.2020.176

10. Fullerton JT, Johnson P, Lobe E, et al. A Rapid Assessment Tool for affirming good practice in midwifery education programming. Midwifery. 2016;34:36-41. doi:10.1016/j.midw.2016.01.008

11. Mrunalini M, Chandekar PA. Factors affecting the teaching-learning in nursing education. Am Res J Nurs. 2015;1:4.

12. Gaberson K, Oermann M, Shellenbarger T. Clinical Teaching Strategies in Nursing [Internet]. New York: springer publishing company; 2015. Available from: www.repository.embuni.ac.ke/ .../ClinicalTeachingStrategiesinNursing. Accessed April 5, 2019.

13. Federal ministry of health human resource management. The need for midwife and nurse professionals. Available from: www.moh.gov.et. Accessed March 16, 2021.

14. Kuliukas L, Hauck Y, Sweet L, et al. A cross sectional study of midwifery students' experiences of COVID-19: uncertainty and expendability. Nurse Educ Pract. 2021;51:102988. doi:10.1016/j. nepr.2021.102988

15. Ilankoon M, Gnanaselvam K, Sudath S. COVID-19: impact on undergraduate nursing education in Sri Lanka. J Public Health Res. 2020;9(s1):1916.

16. Angasu Kitaba K, Weldemariam S, Belachew AB, Bekela $T$. Effective clinical teaching practice and associated factors among midwifery educators in public universities of Ethiopia: institution-based cross-sectional study. Adv Med Educ Pract. 2021;12:421-429. doi:10.2147/AMEP.S300049

17. Bonsa A, Tadele F, Ayelign M, Ebissa B. Clinical practice competence of Mettu University nursing students: a cross-sectional study. Adv Med Educ Pract. 2020;11:791-798.

\section{Publish your work in this journal}

Advances in Medical Education and Practice is an international, peerreviewed, open access journal that aims to present and publish research on Medical Education covering medical, dental, nursing and allied health care professional education. The journal covers undergraduate education, postgraduate training and continuing medical education including emerging trends and innovative models linking education, research, and health care services. The manuscript management system is completely online and includes a very quick and fair peer-review system. Visit http://www.dovepress.com/testimonials.php to read real quotes from published authors. 